harpoon penetrated the right lobe of the liver, and on passing the hand backwards along the under surface of the liver the point of the harpoon could be felt projecting through its posterior border. The difficulty of removing the harpoon now presented itself, as it was armed with two sharp, flattened barbs, about three.quarters of an inch long and two inches apart. With considerable difficulty a grooved director was passed down along the shaft of the harpoon, and upon this an incision was made forwards through the liver substance with a bistoury; the harpoon was now pushed backwards in order to disengage its barbs from the liver substance in which they were embedded, and was then easily removed. The peritoneum was washed out with a 1 in 4000 warm perchloride of mercury solution, and nearly half a pint of dark blood-clot removed. The bremorrhage from the wound in the liver proved troublesome and was not checked for nearly half an hour. The abdominal wound was closed with five deep sutures, and a large indiarubber drainage-tube was inserted along the track of the harpoon. The wound was dressed with iodoform and carbolic gauze. The drainagetube was removed on the fifth day, and, with the exception of a rise of temperature to $104^{\circ} \mathrm{F}$. on the evening of the third day, the patient had no bad symptom and was discharged with the wound firmly healed on the twenty- first day after admission.

Corazal, British Honduras.

\section{THE VALUE OF OXYGEN IN OPIUM POISONING.}

BT W. J. C. MerRy, M.B., B.Ch. Oxon.

THE practice of the inhalation of oxygen in cases with embarrassed respiration has been an established fact for some time past, and its use has been attended with varying success. It has been given in asphyxia from coal gas and other causes, and in many acute diseases attended with dyspncea and cardiac failure. Its value, however, in opium poisoning with intense cyanosis, dyspncea, and a flagging pulse, does not seem to have been yet put to the test, and the following case may throw some light on the subject.

A man thirty-two years of age was brought to St. Thomas's Hospital by the police. He had been found lying insensible on the Albert Embankment about half an hour previously, and, all attempts to rouse him proving ineffectual, he was conveyed to the hospital. When I first saw him he was some what, though not greatly, cyanosed, and breathing stertorously about fifteen times per minute. He was quite unconscious, his corneal reflex abolished, his pupils contracted and inactive, bis pulse rapid and weak, and his limbs flaccid. His breath smelt of chlorodyne, and a quantity of brownish fluid with a similar smell was removed from the stomach by the stomach-pump. After this efforts were made to rouse the man from his stupor, and, with this intention, enforced exertions being out of the question, the interrupted current, flagellation, cold aifusion, and strong ammonia to the nostrils were successively tried. The ammonia made him cough slightly, but he responded to this combired treatment only to the extent of indifferent protestations when pressure was applied over the supra-orbital notch. The pulse having shown signs of failure at intervals during this time, hypodermic injections of ether were occasionally administered. At the end of about three hours the patient was very little, if at all, better, and as soon as the battery and other restoratives were discontinued he relapsed into profound coma. The united efforts of three policemen failing to make the patient walk, and his condition at the end of four hours' continuous stimulating treatment being serious, he was sent up to the ward. When seen there shortly afterwards his face was intensely blue, and his lips and fingers livid; respiration was very slow (about eight per minute) and laboured. The pulse was scarcely perceptible and unconsciousness was complete. It was then determined to try the effect of the administration of oxygen. This was given in such a way that only the pure gas, undiluted with air, was breathed, and the inhalation was continued without interruption for twenty minutes. At the end of this time the face had regained a nearly normal colour, the respirations were fuller, easier, and slightly quicker, and the pulse was now perceptible at the wrist, beating regularly about 100 to the minute. The patient was, bowever, still in a state of stupor, though the eyelids now responded slightly to a touch on the cornea. After an interval of about half an hour the inhalation was repeated with marked effect. Shortly after its commencement the man, for the first time, moved in bed and presently opened bis eyes. The whole condition improved so rapidly from this time that before a quarter of an hour had elapsed the patient could tell his name and answer, though in $a$ somewhat rambling fashion, any reasonable question. The inhalations were repeated twice after this for twenty minutes, at intervals of three quarters of an hour, at the enc of which time the patient's condition was so satisfactory that they were discontinued. The man remained in a somewhat drowsy state during the day, but never relapsed into coma, and made a perfect recovery. The patient, on his recovery, alleged that he had drunk two ounce bottles of chlorodyne (a preparation containing, I believe, somewhere about four grains of morphia to the ounce) at midnight--that is, about three hours before the police discovered him. The use of oxygen was suggested by the lividity of the patient and by recent observations upon the destructive effect, apparently by oxidation, of potassium permanganate on morphia. That the oxygen was the turning-point in the case seems to be beyond doubt; but of the exact way in which it acted it is difficult to speak without further experience of its use in similar cases.

I am indebted to Dr. Payne for permission to publish the case St. Thomas's Hospital, S. E.

\section{A}

$\mathrm{OF}$

\section{HOSPITAL P RACTICE BRITISH AND FOREIGN.}

Nulla autem est alia pro certo noscendi via, nisi quamplurimas et mos borum et dissectionum historias, tum aliorum tum proprias collectas habere, et inter se comparare.-MORGAGNI De Sed. et Caus. Morb., lib. iv. Procemium.

\section{ST. THOMAS'S HOSPITAL.}

A CASE OF RUPTURE OF URETHRA TREATRD BY IMMEDIATE SUTURE OF THE DIVIDED ENDS ON THE CANAL; BECOVERY.

(Under the care of Mr. William ANDenson.)

ANY method of treatment which is likely to save the subject of a ruptured urethra from the serious results of a traumatic stricture is deserving of attention, and the methoc described in Mr. Anderson's case is the one which is best calculated to do so. It is most likely to succeed when employed early, but it is not infallible, for when the injury has been severe some sloughing of the urethra, where contused, may follow, and this, combined with the effects of decomposing urine in the tissues, may lead to failure in the most carefully satured wound. A stricture may follow when there is partial rupture only if the onse is treated by the cathether without incision. With regard to these cases of ruptured urethra Mr. Harrison writes: " $\Delta \mathrm{s}$ a matter of fact, I have observed from a considerable number of cases that rupture of the deep urethra treated by perineal section and bladder drainage, whether a catheter can in the first instance be passed or not, is seldom followed by stricture."

A man thirty-two years of age was admitted into st. Thomas's Hospital on Sept. 15th, 1893. The patient, while jumping backwards off a bicycle, alighted straddlewise on the hinder wheel. On admission he was in much pain; the perineum was greatly swollen and dark from extravasation of blood into the tissues. There was no bleeding from the urethra, and no attempt had been made to pass urine. An attempt was made to pass a catheter, bat withont success Fther was then administered, and an incision was made into the" swollen perineum in the median line, exposing a large cavity filled with blood clot. After elearing away the extravasation the urethra was found to be completely divided a short distance in front of the triangular ligament, the two ends being separated by a distance of about an inch. An effort was then made to pass a catheter in the ordinary manner, but this was found impracticable owing to the difficulty of fixing the vesical end of the torn canal. A soft No. 10 olivary catheter was then introduced through the wound into the upper opening and pressed on for some distance into the bladder. The other end of the instrument, 
which had previously been trimmed to a convenient shape, was then passed through the wound into the lower urethral opening and brought out at the external meatus. This done, the two torn margins of the canal were united by catgut sutures, and the wound was dressed with iodoform. Four days later the catheter was withdrawn, and as it had become encrusted with phosphates the patient suffered a good deal of pain. A No. 8 silver catheter was then passed into the bladder under an anæsthetic. The instrument was retained in place for ten days, the tube being Eept clear by occasional injections of boracic acid. After the withdrawal the evacuation of urine could be effected without difficulty, and nothing farther was required beyond the occasional passage of a catheter. The man was discharged on 0ct. 7th, four weeks and a half after admission, and has fince been attending from time to time as an out-patient. There has been no tendency to the occurrence of stricture.

Remarks by Mr. ANDERsoN. - The immediate union of the torn ends of a ruptured urethra around a catheter is not always practicable, but when it can be effected it obriates the tendency to stricture which always follows the bealing of a gap in the urethra by granulation. The passage of a catheter, however, is often attended by considerable difficulty if the instrument is introduced from the external orifice of whe urethra, because the point cannot readily be guided into the resical segment; but the method employed in this case of entering both segments of the canal through the wound will be found both easy and safe.

\section{ROYAL BERKSHIRE HOSPITAL, READING.} 1 CASE OF PERFORATING GASTRIC ULCER; OPERATION; DEATH ON THE EIGHTH DAY; NECROPSY; REMARKS.

(Under the care of Mr. W. J. MaURICE.)

IT is difficult to gauge the exact mortality after perforation of gastric ulcer when treated on the expectant plan. There is no doubt, however, that it is excessively high, and that few cases recover from the inevitable peritonitis. It is certain that a large mortality must always follow this accident, for it is not probable that every case will be diagnosed at a sufficiently early stage to admit of the operation; the friends will not consent when it is proposed ; the amount of immediate shock may contra-indicate surgical procedure; or the patient may be in a place where it is not possible to obtain the necessary help. Mr. Maurice's case is a very usefal contribution to the number of those in which operation has been of advantage in prolonging life, for there is no reasonable doubt that without operation death would have speedily followed perforation. This condition of perforation of gastric ulcer must be placed in the category of those which depend for their successful treatment on the clear recognition by the physician of the fact that medicine is comparatively useless, and that operation 20erformed speedily gives the best and usually the only chance of recovery. We are daily seeing proof of the necessity of operation in perforative peritonitis if the patient is to be saved. The perforation here occurred in its usual site, on the anterior aspect of the stomach and towards the cardiac end, but was readily accessible throngh the medium incision employed. For the notes of the case we are indebted to Mr. T. W. Lochel, house surgeon.

A single woman, twenty-three years of age, was seized on Feb. 250h, 1894, at 7 P.M., with sudden and violent abdominal pain and collapse. The following morning she was seen by Dr. Hurry and Dr. May, and was sent into the Royal Berkshire Hospital with a diagnosis of perforated gastric alcer, On admission at noon she had a furred tongae ; small pulse (120); anxious expression; distended abdomen, especially in the lower part; general tenderness and tympanites rigid recti; legs drawn up. She was not anæmic and her condition was fairly good. She had previously enjoyed excellent health, but had suffered slightly and occasionally from indigestion. At 1 P.M., under chloroform, a four-inch incision was made in the middle line, immediately below the umbilicus, this sitnation being chosen because the chief distension was low down and the diagnosis a little obscure. No general peritonitis was found, but a sponge passed down into Donglas's pouch came up covered with lymph. The appendix, oraries, and tubes having been found to be normal, the incision was prolonged upwards to halfway between the umbilicus and ensiform cartilage, when gas and fluid escaped from its upper angle; it was therefore enlarged still further to the costal margin, with some inclination to the left to avoid a piece of adherent colon. A perforation was now found on the lesser curvature of the stomach near the cardiac end, surronnded by an area of much thickened stomach wall. A stitch was passed through the serous and muscular coats on each side of the perforation, but it cut out at once and the thickened area was so extensive and so rigid that it was evidently impossible either to excise the ulcer or to close the perforation; it was also quite impossible to bring the injured part of the stomach into contact with the abdominal wall. The free anterior wall of the stomach was therefore attached by one silk suture on each side to the upper part of the abdominal wound; the general peritoneal cavity was thus surprisingly well shut off from the enclosed portion above, into which the perforation opened. The lower part of the incision was then closed after careful washing and sponging, a glass tube being left at the lower extremity to drain Douglas's pouch. The upper two inches were left open and a large rubber tube was passed through into the stomach, the distance between the abdominal wall and the ulcer being three inches. The dressings were so arranged as to keep the upper and lower portions of the wound as far as possible distinct. The operation lasted about one hour. The patient rallied well, but one-third of a grain of morphia was given at night, as she had a little pain. On the fourth day the glass tube was removed, as it was perfectly dry. On the fifth day she seemed rather weak, but there had been no vomiting at any time and no tenderness or distension, and the abdominal muscles moved well. The highest temperature was $100^{\circ} \mathrm{F}$. on the night of the operation; the pulse had fallen from 120 to 104 . She had been fed entirely per rectum. On the sixth day she was decidedly weaker; peptonised beef-tea by the stomach produced no improvement. On the seventh day at 3 A.M. she had an attack of pain-the first since the day of the operation. It was completely removed by an injection of morphia (1 gr.), bat her pulse was growing weaker and quicker, and though there were no other bad symptoms she was evidently becoming worse. She died at 3 P.M. on the eighth day after the operation.

Necropsy.-Beyond a little suppuration about some of the stitches, a very small amount of superficial pus beneath the wound, and a patch of lymph the size of half a crown between the spleen and the diaphragm everything was satisfactory. The pelvis was perfectly dry and healthy, and the stomach was securely fixed to the abdominal wall. All the organs seemed normal.

Remarks by Mr. MaURICE. -1. The operation relieved pain, prolonged life, and gave a chance of recovery. 2. The low incision in this case revealed the presence of pelvic peritonitis. Perhaps in any sirnilar case it might be well to make a small opening below the umbilicus for the purpose of exploring and, if necessary, draining the pelvis. 3. The simple suturing of the stomach to the abdominal wall secured perfect coaptation and suggests the possibility of success by a rapid operation, even in the presence of much shock. 4. Perbaps feeding should have been begun sooner, but when it was begun it produced no improvement. It is impossible to say how much of the beef-tea escaped into the dressings. Possibly the tube might have been passed on into the pylorus, or, on the other hand, no tube might have been used and the wound packed with gauze instead. 5. It would be interesting to know what exactly was the canse of death. Peritonitis was practically absent and nothing suggests toxæmia.

Mr R. Kimpton, the oldest bookselier in London and probably England, whose name has been familiar to generations of medical students, died on the morning of Saturday, May 26th, aged ninety-one years. He began his business as a bookseller over fifty years ago; and during his half century of active work it is no exaggeration to say that the majority of London medical students have dealt with him.

Great Northern Central Hospital.-The committee of this free charity has received the sum of $\$ 400$ from the trustees of Smith's (Kensington Estate) Charity, towards the large debt on the maintenance fund. The committee have elected as their secretary Mr. Lewis $\mathbf{H}$. Glenton Kerr, late assistant secretary at the Middlesex Hospital. 